\title{
Presença da música e da dança em Sagrada Esperança de Agostinho Neto ${ }^{1}$
}

\author{
Xosé Lois García \\ Poeta e ensaista
}

\begin{abstract}
RESUMO: PARA ENTENDER SATISFATORIAMENTE O UNIVERSO DA POESIA AFRICANA É IMPORTANTE ESTAR A PAR DAS COMPETÊNCIAS ORIGINADAS DE SEU ESPÍRITO EMANCIPADO E LIVRE, DO QUAL PARTICIPAM TAMBÉM A MÚSICA E A DANÇA. ESTE TEXTO TEM O OBJETIVO DE ANALISAR EXEMPLOS DA TEMÁTICA DA MÚSICA E DA DANÇA NA POÉTICA DE AGOSTINHO NETO, EM SUA OBRA PRIMA SAGRADA ESPERANÇA, LEVANDO EM CONSIDERAÇÃO O FATO DESTE POETA ANGOLANO TER ASSUMIDO E EXALTADO EM SEUS VERSOS UM MUNDO DO QUAL FOI TESTEMUNHA OCULAR.
\end{abstract}

ABSTRACT: FOR UNDERSTANDING SATISFACTORILY THE UNIVERSE OF THE AFRICAN POETRY IT IS IMPORTANT TO BE AWARE OF THE COMPETENCES THAT EMERGE FROM ITS FREE AND EMANCIPATED SPIRIT, FROM WHICH ALSO PARTICIPATE THE MUSIC AND THE DANCE. THIS TEXT AIMS TO ANALYZE SAMPLES OF MUSIC AND DANCE THEMES IN THE POETICAL WORK SAGRADA ESPERANÇA (SACRED HOPE), BY AGOSTINHO NETO, AN ANGOLAN POET THAT ASSUMED AND EXALTED A WORLD HE WAS AN EYEWITNESS.

PALAVRAS-CHAVE: POESIA ANGOLANA, AGOSTINHO NETO, SAGRADA ESPERANÇA, MÚSICA, DANÇA.

KEYWORDS: ANGOLAN POETRY, AGOSTINHO NETO, SACRED HOPE, MUSIC, DANCE.

1 Título original em galego: "Presencia de la música y de la danza en Sagrada Esperanza de Agostinho Neto". Tradução de Sueli Saraiva 
á muito tempo tem chamado minha atenção a personagem Caliban, de William Shakespeare, da peça "A Tempestade". Caliban era dono de uma ilha e nela foi escravizado e espoliado pelo estrangeiro que ali chegara. Por meio dos convincentes argumentos de Caliban - em seu enfrentamento das contraditórias e sempre justificadas intenções etnocêntricas por parte do intruso colonizador, chamado Próspero - Shakespeare oferece a nós, críticos africanistas, o desvelamento da alteração de uma parcela do universo africano por meio da ocupação colonial. O diálogo entre duas personagens da peça shakespereana deixa claro a marcha da máquina colonial e racial, contrapondo as intenções de Caliban de recuperar sua liberdade e sua cultura original. Caliban pode então apenas sonhar com aquela realidade alterada e menosprezada. Na cena, um dos algozes de Caliban, Estefânio, teme os "movimentos da natureza" à sua volta; mas Caliban, revelando a intimidade com o lugar que é "seu", e profere:

Não fiqueis com medo. A ilha está sempre cheia de rumores, de sons, de suaves melodias que deleitam e não causam dano. Às vezes, um milhar de instrumentos vibrantes ressoa em meus ouvidos e, outras vezes, são vozes que, se então tivesse acordado depois de longo sono, fariam com que dormisse novamente. ${ }^{2}$

Os povos colonizados da África entroncaram-se nesta cultura calibanesca em seu desejo de permanecerem íntegros e aspirar a um patrimônio ancestral, onde a música e a dança estão intimamente ligadas a todas as expressões de uma cultura, que faz com que cada pessoa, amparada nestes sonhos, se torne consciente de que a renúncia não é possível - remetendo a outra obra de Agostinho Neto.

É neste contexto que os poemas de Agostinho Neto se radicam nas essências mais íntimas da tradição ancestral. Em último caso, já não é necessário ter consciência de raça ou de classe para se dar conta da magnitude da discriminação sofrida. Além disso, o poeta tem consciência de sua própria cultura, de sua própria realidade e dos preconceitos sustentados pela burguesia colonial. Ele busca a legitimidade da diferença como base de sua própria idiossincrasia

2 SHAKESPEARE, W. "A tempestade". Ato III; Cena II. Tradução de Oscar Mendes. In: Obras completas. Rio de Janeiro: Nova Aguilar, 1988, Vol. II, p. 945. 
e de seu próprio ser. E ser africano significa que os sons da "melodia crepitante das palmeiras" só podem ser reconhecidos no ciclo do próprio canto da natureza, pelos próprios nativos. Há neste ponto uma harmonia entre o homem e a natureza: medida de todas as coisas; comunhão inseparável que faz exclamar o poeta:

A música
que a minha alma sente

(“Sinfonia”)

À medida que transitamos pela sinfonia descritiva que Agostinho Neto sente e vive, apreciamos a intimidade desse descobrimento emocional e espiritual mediante uma série de instrumentações dadas nos versos. Assim, veremos a interrelação calibanesca no próprio canto e sonho do poeta angolano. Seus gritos eclipsados pelas contingências de seu tempo e espaço renascem em Sagrada Esperança. O poema "Aspiração" ilustra o que é dito:

E sobre os meus cantos

os meus sonhos

os meus olhos

os meus gritos

sobre o meu mundo isolado

o tempo parado.

(“Aspiração")

Os versos, mesmo abordando uma situação particular sob a colonização de Angola, sugerem uma série de matizes e correspondências que remetem às palavras de Caliban. Neste sentido, concluindo esta argumentação, ouçamos as palavras do poeta nacional de Angola:

\footnotetext{
Ainda o meu espírito

ainda o quissange

a marimba
} 
a viola

o saxofone

ainda os meus ritmos de ritual orgíaco.

("Aspiração")

Aqui destacamos o verso "ainda os meus ritmos de ritual orgíaco", o qual, além da instrumentação acima referida, que possibilita uma aproximação à musicalidade africana, também indicia a sonorização dos ritmos ancestrais em um determinado ritual da África.

\section{Cantares da terra}

No poema "Pausa", Agostinho Neto volta a falar do "cântico da terra". Retomemos a análise desse cântico. Nele, música e dança sintetizam a totalidade de um continente e de gentes impregnadas de ancestralidade; no entanto, o último verso pressupõe a modernidade integrando-se no cântico antigo para o devir de uma nova África. Os quatro versos finais concretizam, intencionalmente, o esforço dos braços que fazem retumbar as essências da África para além de qualquer fronteira geográfica e artificial imposta pelo colonialismo. Diz o poeta:

E entre a angústia e a alegria

um trilho imenso do Níger ao Cabo

onde marimbas e braços tambores e braços vozes e braços

harmonizam o cântico inaugural da Nova África.

("Pausa")

A partir dessa imensa África mencionam-se diversos trilhos onde os corações batem ritmados e os pés dançam nas noites de fogueiras. Agostinho Neto relaciona passado e presente, duas atribuições com as quais se forja o futuro, ou pelo menos que lhe servem de caminho para sonhos e desejos: 
Pelo futuro eis os nossos olhos

Pela Paz eis as nossas vozes

Pela Paz eis as nossas mãos

da África unida no amor.

("Sangrantes e germinantes")

Somente as vozes, sem nenhum instrumento nem dança, exaltam esse hino monódico pelo futuro, pela paz e amor de uma África unida. Agostinho Neto insiste tanto na ancestralidade como no universo telúrico da realidade africana. Ele é um dos poetas africanos que melhor encarna e insiste na importância da negritude universal e da africanidade, expressando-a com todo o sentimento que flui de seu eu africano. Negritude e africanidade que também se manifestam na dança e nos cânticos, os quais, por sua vez, emanam tanto de um pensamento milenar quanto de pautas e comportamentos sociais do tempo presente. Esta africanidade, em todos os seus componentes, legitimam e revelam as essências mais puras, que Agostinho Neto canta nestes versos:

\author{
Sim! \\ à interrogação mágica de Talamungongo \\ do Cunene ou do Maiombe, \\ ao sonoro cântico de ritmo subterrâneo \\ e dos chamamentos telúricos; \\ aos tambores \\ apelando para o fio da ancestralidade \\ esbatida aqui e além; \\ ao ponto interrogativo de Madagáscar.
}

("Poema")

Há versos tão invocadores quanto persistentes, nos quais o poeta deseja que seus compatriotas estudem, recuperem e manifestem essa ancestralidade agredida e lesionada por comportamentos estrangeiros. Por exemplo: 
também tu

harmonia sagrada e ancestral

ressuscitada nos aromas sagrados do Ngola Ritmos.

(“O içar da bandeira”)

Agostinho Neto manifesta seu júbilo quando essa ancestralidade se exterioriza nos diversos foros da modernidade, como foi o caso do famoso grupo musical, o "Ngola Ritmos", que tanto contribuiu com uma música combativa no processo de Libertação Nacional de Angola. Ao apelo à ancestralidade deve-se acrescentar todo o peso da cultura existencial angolana, que tanto brilho estelar deu aos filhos da terra, e foi reflexo de uma grandeza cósmica que, na dimensão lírica de Neto, se expressa nos cânticos que brotam de profundas raízes:

Cantam nas praças e nos templos da sabedoria as raparigas os poetas o[s] brilhos das estrelas mergulhadas as raízes no húmus ancestral da África

("A voz igual")

Nesta direção, o poeta é ainda mais específico:

Ressuscitar o homem

nas explosões humanas do dia a dia na marimba no chingufo no quissange no tambor no movimento dos braços e corpos nos sonhos melodiosos da música.

("A voz igual")

Outra das variantes que apreciamos na poesia de Agostinho Neto, com respeito à música, diz respeito aos apelos feitos à ordem tradicional, recorrendo-se ao passado para cultivar o presente com sons reveladores do modo de ser e estar dos africanos. Sua africanidade é feita de sólidos componentes 
metafísicos e de uma convicção profundamente angolana. Em todo este tecido poético desvela-se um conjunto de valores que engloba desde o contexto local de seu microcosmo até o macrocosmo. É por meio de tais recursos que a universalidade de conteúdos na poesia de Agostinho Neto põe a claro e fortalece a nobre e ampla cultura da negritude, da qual a música e a dança são expressões que revelam, pontualmente, as essências africanas:

A liberdade nos olhos

o som nos ouvidos

das mãos ávidas sobre a pele do tambor

num acelerado e claro ritmo

de Zaires Calaáris montanhas luz

vermelha de fogueiras infinitas nos capinzais violentados

harmonias spiritual de vozes tamtam

num ritmo claro de África.

("O Caminho das estrelas")

No poema "À Reconquista” lemos:

Vem comigo África de calças de fantasia

desçamos à rua

e dancemos a dança fatigante dos homens

o batuque simples das lavadeiras

ouçamos o tam-tam angustioso

enquanto os corvos vigiam os vivos

esperando que se tornem cadáveres.

Depois da leitura desses versos, não nos parece impossível estabelecer uma ordem cronológica para abordarmos essa cultura instrumental da música angolana e de seus componentes, todos eles inseparáveis da dança. Os tam-tams e os batuques são a linguagem fiel e viva de todos os grupos sociais da África que deles se serviram não somente em cerimoniais, mas também para transmitir mensagens de guerra ou de paz, de tristeza ou de Esperança. 


\section{Ancestralidade e resistência}

Todas essas manifestações de música e de dança estão vinculadas à grande mensagem emanada da poesia africana; particularmente, na de Agostinho Neto. Nosso poeta não perde de vista a funcionalidade da poesia tradicional angolana em seu contexto musical e naquilo que representa para a totalidade dos negros. O poema sem a instrumentação musical seria pouca coisa para a maioria das culturas africanas estendidas por todos os hemisférios. Toda a construção de Sagrada Esperança sustenta o fundo musical que se cria na poesia. Muitas vezes são os tambores que proclamam o que dizem os rapsodos, como acontece com os yorubás da Nigéria e de outras partes da África.

Agostinho Neto é um poeta que não somente enfatiza o ser humano em quase todos os seus estados anímicos, relativamente ao contexto angolano, mas também trata de resgatá-los e colocá-los em seu meio cultural. Neste aspecto, observamos o poeta em sua obsessão por preservar os angolanos dentro de seu próprio estado criativo e evolutivo, com todos os atributos oriundos da vida tradicional. São desta ordem os elementos sugestivos de sua poesia, na qual a música e a dança têm uma função prioritária e também revolucionária que ultrapassa conceitualidades expressivas.

Eis a força libertadora que surge do poema para evocar e implicar os gritos dos tam-tams como forma de resgatar as nações africanas e incutir nelas o amor a si mesmas:

Os nossos gritos

são tamtams mensageiros do desejo

nas vozes harmoniosas das nações

os nossos gritos são hinos de amor para os corações

florescendo na terra como no sol nas sementes

gritos África

gritos das manhãs em que nos crescem os cadáveres

acorrentados

sangrantes e germinantes

(“Sangrantes e germinantes") 
O poeta e presidente personificou nos tambores a humilhação e a negação dos negros em suas múltiplas escravidões. Essa pele envelhecida, curtida de tantos golpes da irracionalidade repercute no poeta e o faz sentir-se ferido como o seu povo:

ao lado de ritmos de dedos congestionados

sobre a pele envelhecida do tambor

dentro do qual vivo e vibro e calmo:

\section{AVANTE!}

("Na pele do tambor")

Este lamento contundente pela África sofrida e colonizada, transmitido pelo batuque suplicante, lhe serve de denominador comum para todas as experiências, suas e de outros. As metáforas que percorrem seus poemas sintetizam a dor de Angola, estendida a toda a África, conforme os seguintes versos:

nos batuques choro de África

nos sorrisos choro de África

nas fogueiras choro de África

nos sarcasmos no trabalho na vida choro de África.

("O choro de África”)

Em Sagrada Esperança encontramos segregações trágicas que manifestam a situação dos angolanos "abandonados ao ritmo dum batuque de morte" ("Adeus à hora da largada"). Este verso tão contundente de Agostinho Neto revela uma situação tremendamente subumana na qual o homem é um objeto que simplesmente tenta sobreviver nesse ritmo de batuque de morte. Desta situação sobressai uma série de exemplos cabais das sequelas do poder colonial.

Neste processo poético encontramos o nativo tentando superar a sua condição de interdito e submisso; aglutinando forças para alcançar movimentos, ritmos ao som da batucada. Portanto, a música - insistimos - além de cumprir várias funções de tipo antropológico, cumpre uma função social, e também de classe. No poema "Sábado nos musseques" está dito: 
Ansiedade

no som da viola

acompanhando uma voz

que canta sambas indefinidos

deliciosamente preguiçosos

pejando o ar

do desejo de romper em pranto

(“Sábado nos musseques”)

Este poema é o testemunho de um acúmulo de ansiedades que se manifestavam nas salas de baile e que muitas vezes a alegria é alterada pelo "namorado repreende a noiva" (idem). Agostinho Neto descreve, na chave da dialética existencial, os eventos, as controvérsias do homem colonizado, degradado a ser cidadão de última classe em sua própria pátria. Essas degradações típicas de qualquer sujeito colonizado, tal como as estudou Frantz Fanon, têm na música e na dança o seu momento de pausa.

Esta não é uma tipologia exclusiva de Angola. O tema da música e da dança, em toda África, tem conotações mais amplas e profundas. Os bairros mencionados por Agostinho Neto organizam batucadas para amenizar as agruras do cotidiano, da miséria, da perseguição policial etc, como se menciona nestes versos:

E de repente

no bairro acabou o baile

e as faces endurecerem na noite

Todos perguntam por que foram presos

ninguém o sabe

e todos o sabem afinal

\section{("Crueldade”)}

Não há neste esforço um propósito de dançar para esquecer, é um esforço de rostos endurecidos na noite, tomando-se a noite como metáfora de 
crueldade. Mas também o que se sugere é um esforço de construir. Tal como expressa o poema "Confiança": "Enquanto o sorriso brilhava/ no canto de dor/ e as mãos construíam mundos maravilhosos".

Consideremos igualmente o poema " $\mathrm{Na}$ pele do tambor". Todo ele apresenta a conexão mais surpreendente de uma série de aspectos, já não mitológicos, mas sim funcionais, como resultado operante do grande esforço do homem africano, que o poeta compara com a pele do tambor. Trata-se de uma metáfora ilustrativa como tantas outras que aparecem no contexto da música e da dança na poética de Agostinho Neto. Aqui existe uma denúncia clara do mundo da exploração:

Vibro no couro pelado do tambor festivo em europas sorridentes de farturas e turismos sobre a fertilização do suor negro.

("Na pele do tambor")

Pele batida do tambor que ainda ressoa, como os dorsos oprimidos que brilham ao sol e vibram sob a dureza do açoite. Em suas inquietações, o poeta amplia a metáfora tanto para dar relevo às desigualdades nas relações quanto para explicar as causas reais da opressão de um outro tambor imaginário. Como síntese metafórica, esse tambor (ou o negro) é o combustível que alegra as classes exploradoras, as "europas sorridentes", como demonstram os versos.

No início do poema a representação imagética do oprimido e do opressor traz implícita a proclamação: há de resgatar os seres negados e oprimidos. Neste ponto o poeta é incisivo:

As mãos violentas insidiosamente batem

no tambor africano

e a pele percutida solta-me tam-tams gritantes

de sombras atléticas

à luz vermelha do fogo de após trabalho.

("Na pele do tambor") 
Esse mesmo tambor acompanha os cânticos fúnebres e que produz ecos emitidos de peles inertes, e convertidas em choro. E aqui encontramos muitos indícios interrelacionados em Sagrada Esperança; ainda que tais pessoas não efetivassem esse choro, a própria natureza o faria por elas no cântico sussurrante das palmeiras, compassado pela própria pele do tambor, como assinala Agostinho Neto:

- quando num óbito o tambor chora um cadáver

e as raparigas cantam -

("Noites de cárcere”)

Uma leitura atenta de Sagrada Esperança mostra que há no final do livro um insistente e clamoroso lamento épico. Tanto o tambor quanto as danças têm um enorme protagonismo a favor da luta contra a escravidão e o servilismo colonialista. De dentro da prisão, Agostinho Neto afirma:

Aqui no cárcere

eu repetiria os heróis

se alegremente cantasse

as canções guerreiras

com que o nosso povo esmaga a escravidão.

("Aqui no cárcere”)

Foi precisamente nas prisões de Aljube e Ponta do Sol, em 1960, que ele escreveu os poemas "Depressa", "Luta", "Campos verdes", "Havemos de voltar", "Desterro" e "A voz igual". Em todos eles há uma exaltação à luta para reconquistar a dignidade dos angolanos. São todos versos de emancipação, como os seguintes:

Escorracemos o inimigo

e cantemos numa luta viva e heróica

desde já

a independência real da nossa pátria

("Depressa") 
Agostinho Neto, como dirigente e homem comprometido com esta luta, sentiu no cárcere "as vozes em coro na impaciência" ("Campos verdes"). Seus versos são lapidares nesta questão:

Violência

vozes de aço ao sol

incendeiam a paisagem já quente

("Luta")

Observemos como o poema a seguir reclama, sem reservas, a tradição dos cânticos angolanos e conclama a cultivar as particularidades linguísticas do passado ancestral. A disposição de preservar e universalizar a singularidade do povo angolano em suas diversas idiossincrasias se manifesta nestes versos reveladores:

$\mathrm{Na}$ hora das transformações humanas

o chilreio infantil da mocidade feliz

cantando em rodas ensaiadas pelos avós

falando nas nossas línguas a tradição da nossa terra

harmonizando as vozes na hora da independência

("A voz igual”)

E nestes versos insiste-se sobre a funcionalidade da música e suas incontinências:

e de sonoras palavras nas letras das músicas desesperadas lançadas nos bailes de sábado sobre as poeiras dos quintais e o desejo incontido de se realizar de ser homem de encontrar o calor supremo na superfície carnal do outro.

(“A voz igual”) 
Agostinho Neto encerra esta questão com um enfático apelo para que o ritmo se transforme em luta cotidiana e popular. Para que as vozes de dor possam ser esgrimidas como uma arma potentíssima em defesa das tradições musicais de África:

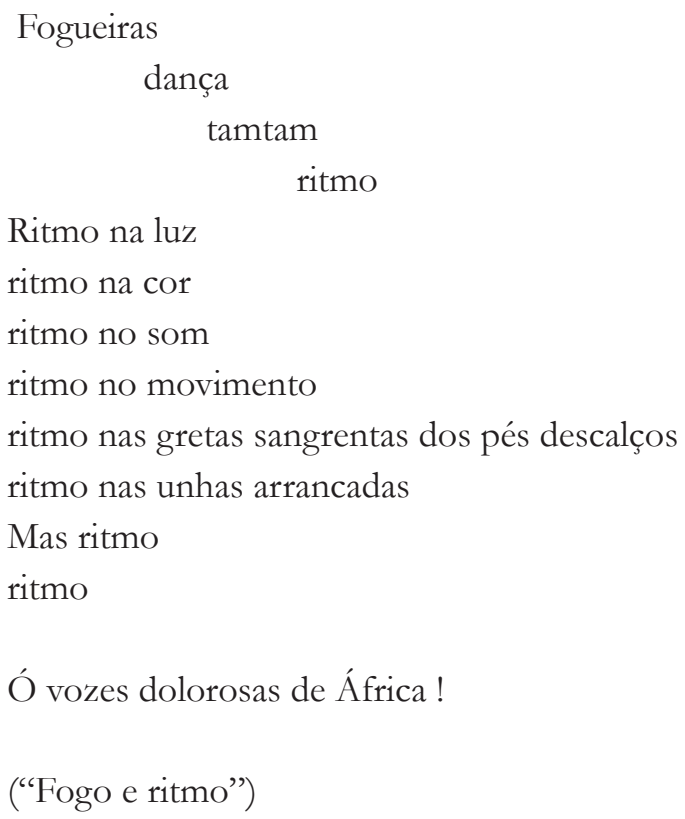

Música e dança na poesia de Agostinho Neto servem de coesão e de possibilidade de tomada de consciência sobre a situação colonial, para a alteração do processo político existente e para encontrar novas expressões que reafirmem a legitimidade da cultura nacional angolana. Tais proposições, referentes à cultura nacional e mesmo à negritude remetem, sem dúvida, às palavras de Frantz Fanon:

Podríamos igualmente buscar y encontrar, en el plano de la danza, del canto melódico, de los ritos, de las ceremonias tradicionales el mismo impulso, advertir las mismas mutaciones, la misma impaciencia. Mucho antes de la fase política o armada de la lucha nacional, un lector atento puede sentir, pues, y ver cómo se manifiesta el nuevo vigor, la lucha próxima. Formas de expresión desacostumbradas, temas inéditos y dotados de una fuerza no ya de invoca- 
ción sino de agrupación, de convocación "con un fin". Todo concurre para despertar la sensibilidad del colonizado, para hacer inactuales, inaceptables, las actitudes contemplativas o de fracaso. Al renovar las intenciones y la dinámica de la artesanía, de la danza y de la música, de la literatura y la epopeya oral, el colonizado reestructura su percepción. El mundo pierde su carácter maldito. Se dan las condiciones para la inevitable confrontación. ${ }^{3}$

Mais adiante Fanon continua enfatizando o papel da cultura nacional: "Esta nueva humanidad, para sí y para los otros, no puede dejar de definir un nuevo humanismo. En los objetivos y los métodos de la lucha se prefigura ese nuevo humanismo" (FANON, 1963, p. 151).

O apelo à idiossincrasia tradicional dos costumes transmitidos de geração em geração, consagrados como fonte de cultura, são aproveitados por Agostinho Neto para sensibilizar de forma aguda e criar condições de permanência do sentimento e da força biológica da cultura nacional. Ou seja, para provocar o despertar as almas de uma imensa e sombria letargia. A música e a dança tornaram possível esse amanhecer, tal qual nos fala Keita Fodeba em seu "Amanhecer africano", do qual extrai o seguinte excerto: "Era o amanhecer. A pequena aldeia que havia dançado durante metade da noite ao som dos tam-tams aos poucos despertava". Esta passagem, em chave metafórica, tem um profundo e estrito significado dentro de qualquer processo histórico da colonização da África.

No poema, "O caminho das estrelas", Agostinho Neto curiosamente insiste no elemento biológico do ser africano e no valor poderoso da música no todo formativo do eu africano. Vejamos como nesse poema tudo aparece de forma mais matizada do que insinuada:

Simples nota musical
Indispensável átomo de harmonia
partícula
germe

3 FANON, Frantz. Los condenados de la tierra. Trad. Julieta Campos. México: Fondo de Cultura Económica, 1963, p. 150. 
cor

na combinação múltipla do humano

(O caminho das estrelas)

O desejo e a esperança de voltar a se encontrar na roda das fogueiras, nos cânticos, nos ritmos e em tudo o que o próprio meio oferece como dádiva e distinção. Aqui o poeta enfatiza:

À frescura da mulemba

às nossas tradições

aos ritmos e às fogueiras

havemos de voltar

À marimba e ao quissangue

ao nosso carnaval

havemos de voltar

(“Havemos de voltar")

No poema "As terras sentidas" continua a mensagem de unidade que o poeta deseja expressar com uma carga de competências que põe em destaque o espaço angolano. Neste ponto é lícito pensar que, a partir desse centro que gira sem parar em forma de espiral, alcança-se nesse movimento rotativo a música e a dança, que perpetuam a dinâmica existencial. Sobre os sonhos e as esperanças pela terra nativa, diz o poeta:

Elas fervilham-nos em sonhos

ornados de danças de embondeiros sobre equilíbrios

de antílope

na aliança perpétua de tudo quanto vive

("As terras sentidas") 


\section{Ecos além-África}

Para Agostinho Neto não existem culturas superiores nem inferiores, existem problemas básicos; teorizações e imposições etnocentristas que servem para degradar e acelerar o conflito, a partir de uma posição que determina o poder político do colonizador. Em sua poesia, Neto dá mostras suficientes de ter percebido, na contraposição dos poderes, que uma pessoa se sente superior e outra se sente diferente, não inferior. Frente a este rol de contradições, as classes dominantes, com todo o seu maquinário e pretensão de "superioridade", estão implicadas numa "superioridade racista".

Neste sentido, a poesia de Agostinho Neto é explícita sobre o papel desempenhado pelas estruturas políticas e econômicas transnacionais que interveem, alterando e dominando a vida autóctone dos diversos povos africanos.

O argentino Néstor García Canclini em seu livro Las culturas populares en el capitalismo, argumenta:

La transnacionalización del capital, acompañada por la transnacionalización de la cultura, impone intercambio desigual de los bienes materiales e simbólicos. Hasta los grupos étnicos más remotos son obligados a subordinar su organización económica e cultural a los mercados nacionales, e estos son convertidos en satélites de las metrópolis, e acuerdo con una lógica monopolista. ${ }^{4}$

E continua o antropólogo argentino:

La diversidade de patrones culturales de objetos e hábitos de consumo, es un factor de perturbación intolerable para las necesidades de expansión constante del sistema capitalista. Al ser absorbidas en un sistema unificado todas las formas de producción (manual e industrial, rural e urbana) son adjuntadas e hasta cierto punto homogeneizadas las distintas modalidades de producción cultural (de la burguesía e del proletariado, del campo e de la ciudad). ${ }^{5}$

4 GARCÍA CANCLINI, Néstor. Las culturas populares en el capitalismo. México: Editorial Nueva Imagen, 1982, p 38.

5 Ibidem. 
Aproximando-nos dessas teses de García Canclini, dizemos que Agostinho Neto está sintonizado a partir de seu localismo intercontinental com as culturas de raízes africanas. E, parte de sua poesia, ao transigir culturalmente além das fronteiras africanas, vislumbra os processos históricos diferenciados e evolutivos de diversos países do continente americano. O poeta angolano, solidário com um tal cenário sócio-cultural, acolhe em sua poesia matizes dispersos dessa cultura comum. Exemplo disso vem expresso nos seguintes versos:

Ainda o meu canto dolente

e a minha tristeza

no Congo na Geórgia no Amazonas

("Aspiração")

O poeta está referenciando nesses versos lugares da África (Congo), mas também dos Estados Unidos (Geórgia) e do Brasil (Amazonas). Na América, a cultura negra teve um impacto e uma transparência capaz de transformar a dinâmica cultural do próprio colonialista. Portanto, esses versos têm uma vocação solidária: perpetuar o sacrifício e o esforço para superar as contradições nas quais haviam sido colocados milhões de escravos. Uma tal identificação, expressada na música e na dança, aparecem nos versos de "Poema": "e nos intervalos/ cantarei canções afro-brasileiras".

No poema "A voz igual" encontram-se seis versos que, por sua profundidade expressiva, percebe-se o universo africano transplantado em todas as Américas. Isso demanda uma análise mais detida dessa comunicação cultural, tendo em mente que nesses espaços as raízes comuns da música e da dança germinaram poderosamente e, por sua dinâmica e criatividade, manifestaramse com originalidade a partir do contexto mais exaltante e resolutivo da África. Os versos a seguir ilustram bem esse ponto:

Povo genial heroicamente vivo onde outros pereceram

de vitalidade ultrapassada na História

alimentou continentes e deu ritmos à América 
deuses e agilidade nos estádios

centelhas luminosas na ciência e na arte

("A voz igual")

Em toda a sua luta revolucionária e intelectual, Agostinho Neto manteve sempre em mente as culturas originárias da África espalhadas pelo continente americano. No que concerne à música e à dança, a poética de Agostinho Neto apresenta características que são fruto de uma busca pragmática e dinâmica a partir do contexto cultural angolano.

Sagrada Esperança é sobretudo um poemário em que se potencia a cultura liberal frente a sistemas irracionais e monolíticos impostos pelo colonizador. Agostinho Neto foi um intelectual universalista que procurou não ignorar o outro; a cultura do outro. Por isso não se dobrou a minifúndios culturais que menosprezam o diferente. Exemplo dessa universalidade são estes dois versos, com os quais encerro este texto:

Cresçam sinfonias de Beethoven

e poemas que o amigo Mussunda não entende.

("O verde das palmeiras da minha mocidade")

\section{Referência Bibliográfica}

FANON, Frantz. Los condenados de la tierra. Trad. Julieta Campos. México: Fondo de Cultura Económica, 1963.

GARCÍA Canclini, Néstor. Las culturas populares en el capitalismo. México: Editorial Nueva Imagen, 1982.

NETO, Agostinho. Sagrada esperança. $7^{\mathrm{a}}$. edição. Luanda: União dos Escritores Angolanos, 1995.

SHAKESPEARE, W. "A tempestade”. Ato III; Cena II. Tradução de Oscar Mendes. In: Obras completas. Rio de Janeiro: Nova Aguilar, 1988, Vol. II, p. 945. 